\title{
Seasonal Fluctuations of Aroma Components of Essential Oils from Larix leptolepis
}

\author{
Mikio Doi ${ }^{1,2 *}$, Kazuki Toeda ${ }^{3}$, Takao Myoda ${ }^{3}$, Yasuyuki Hashidoko ${ }^{2}$, and Takane Fujimori ${ }^{4}$ \\ ${ }^{1}$ Kushiro Industrial Technology Center Institute, Minami 7-2-23, Tottori, Kushiro 084-0905, JAPAN \\ ${ }^{2}$ Graduate School of Agriculture, Hokkaido University, Kita 9 Nishi 9, Kita-ku, Sapporo 060-8589, JAPAN \\ ${ }^{3}$ Department of Food and Cosmetic Science, Tokyo University of Agriculture, 196 Yasaka, Abashiri 099-2493, JAPAN \\ ${ }^{4}$ NODAI Research Institute, Tokyo University of Agriculture, 1-1-1 Sakuragaoka, Setagaya-ku, Tokyo 156-8502, JAPAN
}

\begin{abstract}
Conifer resins are used as chemical raw materials for daily necessities. There have been many reports on the aroma components of turpentine oil from rosin, but there has been no reports on fluctuations in the aroma components through spring to late autumn. We speculated that the aroma components in the essential oils of deciduous coniferous larches might fluctuate during maturation of the foliage. In this study, we focused on the aroma components of larch essential oils and we clarified by multivariate analysis how the aroma components fluctuate during leaf maturation. The results of analysis showed that there was a drastic seasonal fluctuation of the chemical components in larch essential oils, especially in senescent leaves in late autumn. Cryptone and linalool were identified as the characteristic aroma components in essential oil from senescent larch leaves.
\end{abstract}

Key words: aroma component fluctuation, foliage essential oils, Larix leptolepis, Picea glehnii, Abies sachalinensis

\section{Introduction}

Pine resins that are produced by conifers are used as chemical raw materials for daily necessities. The aroma components in the pine resins have recently attracted attention as environmentally friendly materials because they are natural and renewable materials and because of their contribution to the reduction of greenhouse gases ${ }^{11}$.

Hokkaido, the northernmost island of Japan is located in a humid cold-temperate climate region that is suitable for coniferous tree growth. There have been some reports on the aroma components in turpentine oils obtained from conifer resins $^{2-6)}$, in which essential oils from larches, pines and firs in Hokkaido are involved ${ }^{7,8)}$. However, seasonal fluctuations of aroma components with maturation of coniferous leaves were overlooked in those reports. We thus speculated that chemical compositions of foliage essential oils in larches, which are deciduous conifers, might show much more drastic changes according to the seasonal maturation of leaves than the changes in chemical compositions of foliage essential oils in ever-green pines or firs because larches lose their leaves following the quick leaf senescence before the annual winter season. Hence, we expected that the seasonal fluctuations of terpene metabolism in the leaves of larch might cause remarkable qualitative changes of the aroma components in foliage essential oils. In this study, we investigated whether the aroma components in essential oils of larch, pine, and fir in Hokkaido fluctuate by using gas chromatography-mass spectrometry (GC-MS) and multivariate analyses.

\section{Experimental Procedures}

2.1 Plant material and extraction

Branches and leaves of larches (Larix leptolepis) were collected in April, May and June in 2015 and November in 2014 in Onbetsu, Kushiro, Hokkaido (lat. $42^{\circ} 50^{\prime} \mathrm{N}$ and long. $\left.143^{\circ} 5^{\prime} \mathrm{E}\right)$. Fallen leaves of larch were also sampled in November 2014. Larch (Larix decidua) essential oil in France in autumn was purchased from HAVEL Artisanat GmbH (Uznach, Switzerland). Branches and leaves of pines (Picea glehnii) were collected in February, May, June, July, August, November, and December in 2013 in Teshikaga, Hokkaido (lat. $43^{\circ} 23^{\prime} \mathrm{N}$ and long. $144^{\circ} 13^{\prime} \mathrm{E}$ ). In July 2014, the same parts of P. glehnii were collected in Akan, Kushiro, Hokkaido (lat. $43^{\circ} 26^{\prime} \mathrm{N}$ and long. $144^{\circ} 05^{\prime} \mathrm{E}$ ). Branches and leaves of firs (Abies sachalinensis) were collected in February, April, June, and September in 2014, in November and December in 2013, and in June in 2015 in Shimokawa, Hokkaido (lat. $44^{\circ} 08^{\prime} \mathrm{N}$ and long. $142^{\circ} 33^{\prime} \mathrm{E}$ ).

\footnotetext{
*Correspondence to: Mikio Doi, Division of Applied Bioscience, Graduate School of Agriculture, Hokkaido University, Kita 9 Nishi 9 , Kita-ku, Sapporo 060-8589, JAPAN

E-mail: doimikio@abs.agr.hokudai.ac.jp

Accepted April 5, 2019 (received for review January 27, 2019)

Journal of Oleo Science ISSN 1345-8957 print / ISSN 1347-3352 online

http://www.jstage.jst.go.jp/browse/jos/ http://mc.manusriptcentral.com/jjocs
} 
The branches and leaves of larch, pine, and fir were steamdistilled for $8 \mathrm{~h}$ using a 36-L scale apparatus made by Kohga International Trading Co., Ltd (Fukuoka, Japan). Using $5 \mathrm{~kg}$ branches and leaves of larches in each month, 9 $\mathrm{mL}$ (April), $15 \mathrm{~mL}$ (May), $14 \mathrm{~mL}$ (June), $10 \mathrm{~mL}$ (July), 15 $\mathrm{mL}$ (November) and $10 \mathrm{~mL}$ (fallen leaves in November) essential oils were obtained. Using $5 \mathrm{~kg}$ branches and leaves of ever-green pines in each month, $60 \mathrm{~mL}$ (February), 59 mL (May), 63 mL (June), 60 mL (July), 63 mL (July in Akan), $6 \mathrm{~mL}$ (August), $58 \mathrm{~mL}$ (November) and $56 \mathrm{~mL}$ (December) essential oils were obtained. Using $4 \mathrm{~kg}$ branches and leaves of ever-green firs in each month, $210 \mathrm{~mL}$ (February), $220 \mathrm{~mL}$ (April), $220 \mathrm{~mL}$ (June), $210 \mathrm{~mL}$ (September), $200 \mathrm{~mL}$ (November), $200 \mathrm{~mL}$ (December) and $220 \mathrm{~mL}$ (June in 2015) essential oils were obtained. The oils obtained were stored at $4^{\circ} \mathrm{C}$ in a refrigerator prior to analysis.

\subsection{Gas chromatography-mass spectrometry (GC-MS)}

GC-MS analysis was performed using an Agilent 7890N Gas Chromatography-5977A MSD Mass Spectrometer (Agilent Technologies, Santa Clara, CA, USA). The samples were analyzed using fused-silica capillary columns, DB-WAX (polyethylene glycol, $30 \mathrm{~m} \times 0.25 \mathrm{~mm}$ in i.d., film thickness of $0.25 \mu \mathrm{m}$, Agilent Technologies). The oven temperature was programmed to increase from $40^{\circ} \mathrm{C}$ to $230^{\circ} \mathrm{C}$ at a rate of $6{ }^{\circ} \mathrm{C} / \mathrm{min}$ and was held at $230^{\circ} \mathrm{C}$ for 10 min. The flow rate of the carrier gas (helium) was $1.255 \mathrm{~mL} /$ min. The injector and transfer line temperatures were $250^{\circ} \mathrm{C}$, and the ionization energy was $70 \mathrm{eV}$. The mass range was 29-400 amu. One microliter of the sample was injected, and the split ratio was maintained at 1:300. Automated injections were performed with a programmable robotic Gerstel MPS2 Multipurpose Sampler (Gerstel GmbH \& Co. KG., Mulheim an der Ruhr, Germany). The retention indices (RI) were calculated using a series of $n$-alkanes $\left(\mathrm{C}_{7}-\mathrm{C}_{33}\right)$ for the DB-WAX column. The results were calculated as mean values of the injection of essential oil without correction factors. All determinations were performed in triplicate and averaged.

\subsection{Identification of components and statistical analysis}

Deconvolution was done by NIST AMDIS version 2.72. The identification of individual compounds was confirmed by comparing the MS data with published data using Digital libraries (NIST14) and Aroma Office version 6.00 (Nishikawa Keisoku Co. Ltd., Tokyo, Japan). The principal component analysis (PCA) and hierarchical clustering analysis were performed using Agilent Mass Profiler Professional B.12.6.1 and MassHunter Workstation Quantitative Analysis Software Version B.07.00 (Agilent Technologies, Santa Clara, CA, USA).

2.3.1 The principal component analysis (PCA)

PCA score plots in each principal component (PC) is obtained as scoring for peak intensity in the total ion current
(TIC) chromatogram of the respective samples detected by GC-MS, using calculation with profiling coefficients of the two PCs (PC1 and PC2). After the scoring, appropriate coefficient values should be calculated to administer the maximum difference between two samples compared. The horizontal axis in the plot is the scores, and the vertical axis is the variable names. To select the principal component with the largest variance, the axes PC1 (x) and PC2 (y) that make up a new coordinate system show that PC1 having a larger variance than $\mathrm{PC} 2$ is a better representation of the data. The axis labels (\%) at PC1 and PC2 are the primarily contribution, and if the total contribution ratio of PC1 and PC2 is 70-80\%, it should be highly normalized as the principle component score model.

PCA loading plots in each PC were obtained as scoring for peak intensity in TIC chromatogram of the respective samples detected by GC-MS using calculation with profiling coefficients of the two PCs (PC1 and PC2). At the scoring for each compound, coefficient values calculated are administered. The horizontal axis indicates the value of the coefficient (loading) applied to the peak intensity of each compound on TIC chromatogram in PC1 score, and the vertical axis indicates the value of the coefficient (loading) applied to the peak intensity of each compound on TIC chromatogram in PC2 score. The numerical value of each compound shown in the PCA loading plots would be an index whether it affects scoring for PCA. The closer the plots of the compound shown in the PCA loading plot is to the position of the plot indicating the sample on the PCA score plot, the more the compound is characterized as an aroma component in the sample.

2.3.2 Cluster analysis

One line on the horizontal axis represents one substance. Substances detected as a relatively high peak intensity are displayed in a black bar, while substances not detected are displayed in a light grey bar. Substances detected as an intermediary peak intensity are displayed in light black.

\section{Results and Discussion}

\subsection{Main chemical components of the essential oils from larches, pines and firs}

First, we compared aroma components in essential oils obtained from the leaves of larch (Larix leptolepis) (2.8 $\mathrm{mL} / \mathrm{kg}$ fresh weight), pine (Picea glehnii) $(12.5 \mathrm{~mL} / \mathrm{kg}$ fresh weight), and fir (Abies sachalinensis) $(55.2 \mathrm{~mL} / \mathrm{kg}$ fresh weight), all of which were sampled in June. The major aroma components of the essential oils from larch leaves were bornyl acetate $(21.96 \%)$ and $\alpha$-pinene $(18.70 \%)$. On the other hand, the major aroma components of the pine foliage essential oils were bornyl acetate (37.05\%), camphor $(12.60 \%)$, and $\alpha$-pinene $(11.82 \%)$, and those of the fir foliage essential oils were $\alpha$-pinene 
(24.70\%), camphene(18.83\%), $\beta$-phellandrene(11.24\%), and bornyl acetate (13.58\%) (Table 1S). The larch foliage essential oils also contained larger amounts of 3-carene $(2.90 \%)$, terpinolene $(1.94 \%)$, and $\delta$-cadinene $(2.70 \%)$ than those in the pine or fir foliage essential oils. The characteristics of aroma components of larch foliage essential oils determined by our analysis showed good accordance with those priously reported ${ }^{2,5,7,8)}$. The chemical components in both the pine essential oils and fir essential oils are also qualitatively agreeable with those in some previous reports $^{6)}$.

\subsection{Seasonal fluctuations of the aroma components in the foliage essential oils from larch}

Principal component analysis (PCA) was carried out to the aroma components of foliage essential oils of larch, pine, and fir (Fig. 1). The first and the second principal components (PC1 and PC2, respectively)accounted for $44.74 \%$ of the total variance $(27.01 \%$ and $17.73 \%$, respectively). The compositional changes in aroma components in the pine and fir foliage essential oils through the seasons remained in narrow ranges (the lower right and in the upper right regions, respectively). On the other hand, the changes in the larch foliage essential oils showed a relatively broad plotting pattern in the upper left region(Fig. 1). The results of PCA showed that fluctuation of aroma components of the essential oils of larch leaves was greater than those in fir leaves during leaf maturation. The PCA score plot showed the differences among the tree species, but it was not clear which component contributed to the essential difference in the PCA scores among them. Therefore, factor loading of PCA (PCA loading plot) was characterized in order to identify the aroma compounds in each essential oil. In the PCA loading plot, one plot represents one compound and also reflects the degree contributing PC1 and PC2. The compounds characterizing larch essential oils with plots were located to the left of the loading plot graph, and plots characterizing the pine and fir foliage essential oils were located to the lower right and upper right, respectively (Fig. 1S).

Approximately 200 candidates (shown as black or grey plots in Fig. 1S) were detected. Compounds having a relatively large influence on the characteristics of components in larch, pine, and fir foliage essential oils were shown as black plots, and we focused on approximately $60 \mathrm{com}$ pounds (shown as black plots in Fig. 1S). From the loading data among them, we identified 11 compounds that strongly characterize larch, pine, and fir (Table 2S).

Using methods similar to those described above, we also examined the major components monitored by GC-MS with the detection of total ion current (TIC) (Fig. 2S) to characterize the odors of larch foliage essential oils through the seasons. In the PCA score plot graph, the plot representing the aroma components in November was significantly different from those in April, May, June and July (Fig. 2). PC1 and the $\mathrm{PC} 2$ accounted for $69.78 \%$ of the total variance

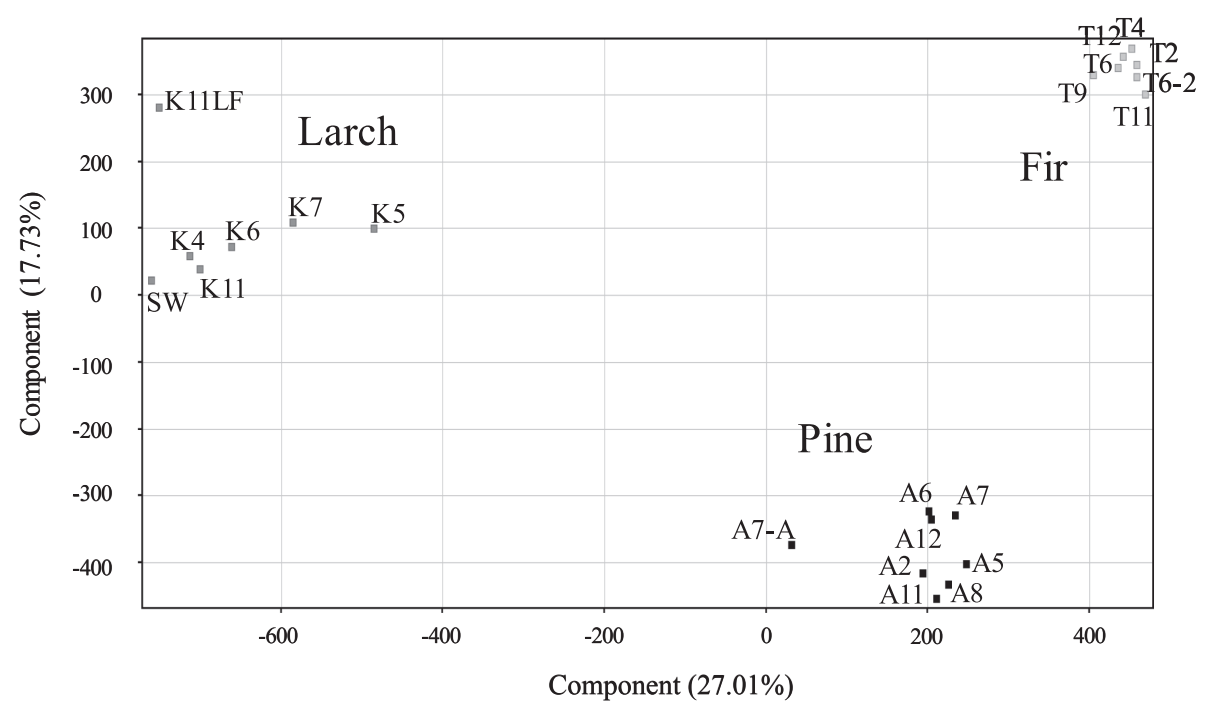

Fig. 1 Comparison of three coniferous foliage essential oils (larch, pine, and fir) by PCA score plots.

K4: Larch (Larix leptolepis) foliage essential oil in April, K5: Larch foliage essential oil in May, K6: Larch foliage essential oil in June, K7: Larch foliage essential oil in July, K11: Larch foliage essential oil in November, K11LF: Larch essential oil from only fallen leaves in November, SW: Larch (Larix decidua) essential oil in France, A2: Pine (Picea glehnii) essential oil in February, A5: in May, A6: in June, A7: in July, A8: in August, A11: in November, A12: in December, A7-A: Pine (Picea glehnii) essential oil of Akan in July, T2: Fir(Abies sachalinensis) essential oil in February, T4: in April, T6: in June, T9: in September, T11: in November, T12: in December, T6-2: in June two years later 


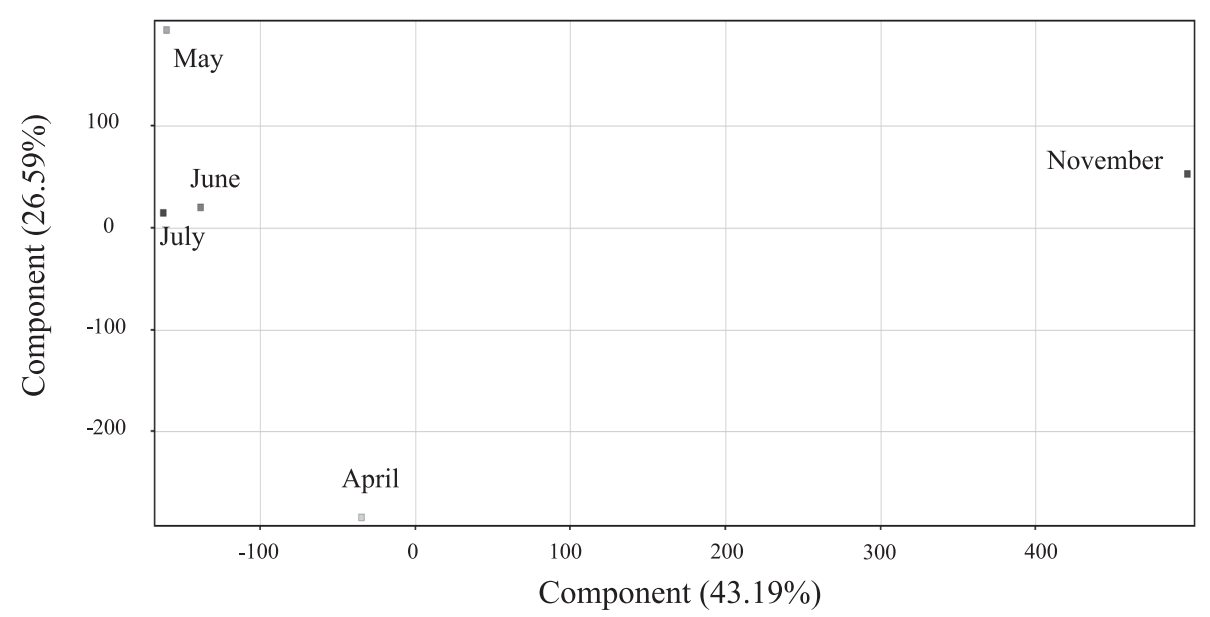

Fig. 2 Comparison of aroma components in larch foliage essential oils by PCA score plots through seasons.

Table 1 Aroma components characteristic to larch foliage essential oil in each month.

\begin{tabular}{|c|c|c|c|}
\hline & Compounds ${ }^{\text {a) }}$ & PC1 loading ${ }^{\text {b) }}$ & PC2 loading ${ }^{c}$ \\
\hline April & rose oxide & 0.086 & -2.109 \\
\hline May & $\beta$-pinene & -1.268 & 1.793 \\
\hline \multirow{7}{*}{ June, July } & tricyclene & -2.118 & -0.502 \\
\hline & toluene & -2.177 & -0.458 \\
\hline & 1,8-cineole & -2.124 & -0.294 \\
\hline & $p$-mentha-1,5,8-triene & -2.159 & 0.079 \\
\hline & $d$-camphor & -2.198 & 0.048 \\
\hline & isopinocamphone & -2.144 & -0.511 \\
\hline & $\delta$-cadinene & -1.968 & 0.302 \\
\hline \multirow{2}{*}{ November } & cryptone & 2.036 & 0.359 \\
\hline & linalool & 2.056 & 0.666 \\
\hline
\end{tabular}

a) Compounds: Identification of each aroma component was carried out on the basis of the mass spectrum and RI.

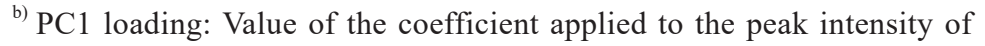
each compound on TIC in PC1.

c) PC2 loading: Value of the coefficient applied to the peak intensity of each compound on TIC in PC2.

(43.19\% and $26.59 \%$, respectively). This variance value indicated that the aroma components in the larch foliage essential oils at the leaf senescence stage in November were significantly different from those in photosynthesizing stages (April to July). There were short but significant distances between the plots representing the aroma components of essential oils in April to May and the plots for those in June to July (Fig. 2), indicating compositional differences of the aroma components in the larch foliage essential oils sampled from newly developing leaves (April to May) and mature leaves (June to July). Thus, seasonal fluctuation of the aroma components was a unique characteristic of the larch foliage essential oils, and the aroma components in the oils of sampled in November larch leaves were 


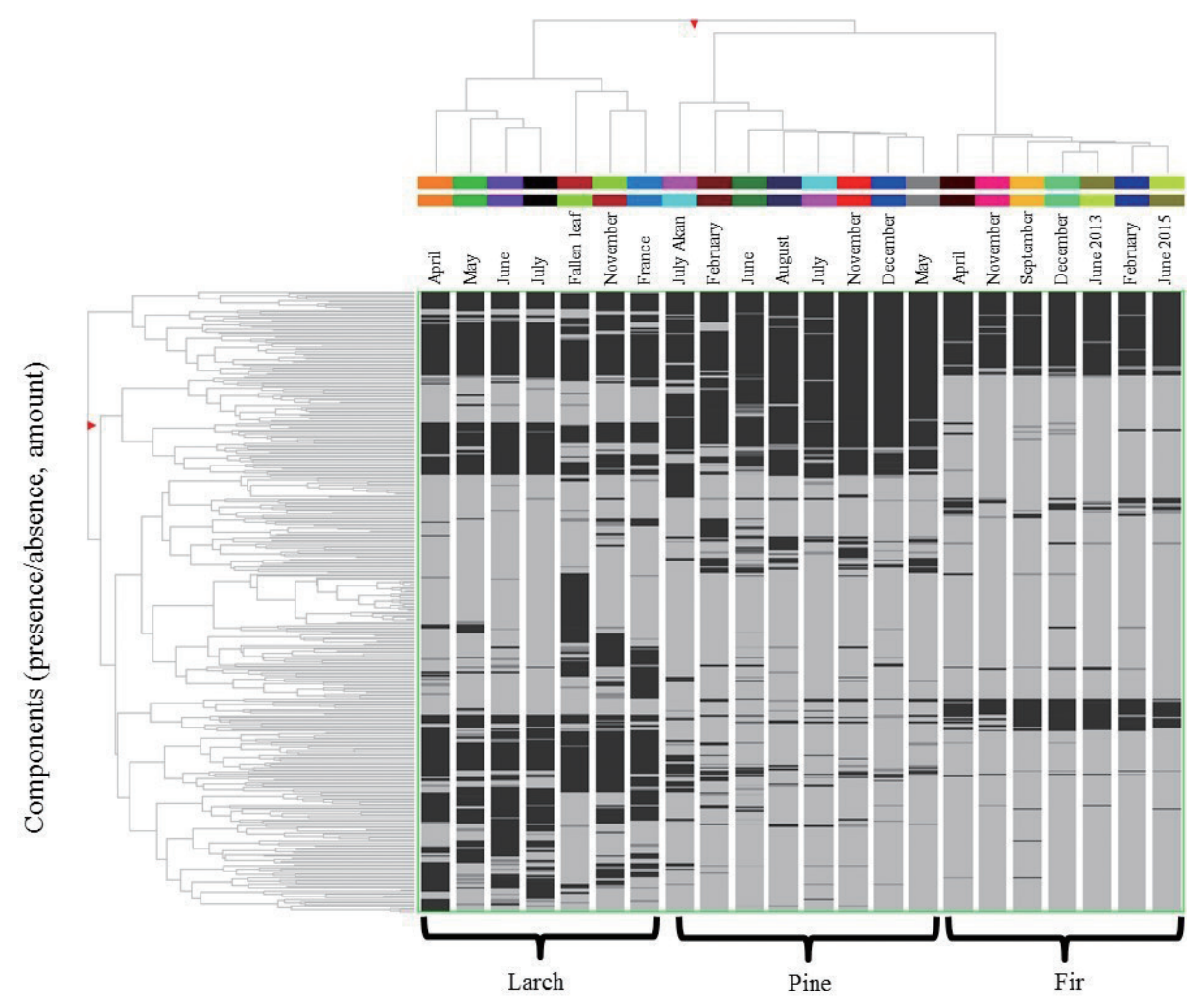

Fig. 3 Cluster analysis of three coniferous foliage essential oils.

Substances detected as a relatively high peak intensity are displayed in a black bar, while substances not detected are displayed in a light grey bar. Substances detected as an intermediary peak intensity are displayed in light black.

particularly different from those sampled in other months.

We performed the PCA loading plot(Fig. 3S) and identified the aroma components to characterize the larch foliage essential oils through the seasons (Table 1). The characteristic aroma components of larch foliage essential oil in the leaves at the senescence stage (November) were cryptone $(1,0.17 \%$ in essential oil) and linalool (2, 0.07\% in essential oil). The characteristics and qualities of the odors of substances 1 and 2 was, according to description in the database Aroma Office version 6.00, as follows: a sweet, herbal and woody citrus-like scent for 1 and a clean note, tea-like and orange-like scent for 2 . The amounts of cryptone(1) and linalool(2)were small in larch foliage essential oils from senescent leaves. However, it is known that the characteristic odor of each essential oil is affected by the composition of the aroma components, including some minor components ${ }^{9)}$. Hence, the larch foliage essence oils from senescent leaves collected in November may provide a high quality of fragrance as a sweet citrus smell, unlike other coniferous foliage essential oils.

\subsection{Cluster analysis of larch foliage essential oils}

In order to reveal and confirm the seasonal fluctuations of chemical components in larch foliage essential oils, cluster analysis based on GC-MS data for larch, pine and fir foliage essential oils collected from leaves in different months was carried out (Fig. 3). The horizontal axis represents each sample and the vertical axis represents the aroma components. The cluster dendrogram of the horizontal axis showed that larch foliage essential oil in leaves collected in November and also the fallen leaves was significantly different in the chemical composition of aroma components from other oils collected from photosynthesizing leaves (April, May, June, and July) . Interestingly, chemical components in Larix decidua foliage essential oil from France were similar to those in our larch (Larix leptolepis) essential oil of larch leaves sampled in November. It is not clear when the leaves used for the L. decidua foliage essential oil from France were collected, but our analysis suggests that they might have been collected at a leaf senescent stage. In contrast, both pine (Picea glehnii) and fir (Abies sachalinensis) showed similar aroma compositions in foliage essential oils through the seasons. These results are consistent with the conclusion obtained from the result of PCA (Fig. 1).

Finally, we investigated the major aroma components in the larch foliage essential oil that showed drastic composition changes during leaf maturation and senescence. Candidates of the aroma components were selected from data obtained by the cluster analysis. We focused on four aroma 


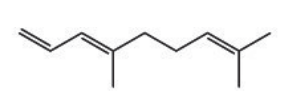

(E)-4,8-dimethylnona-1,3,7-triene (3)
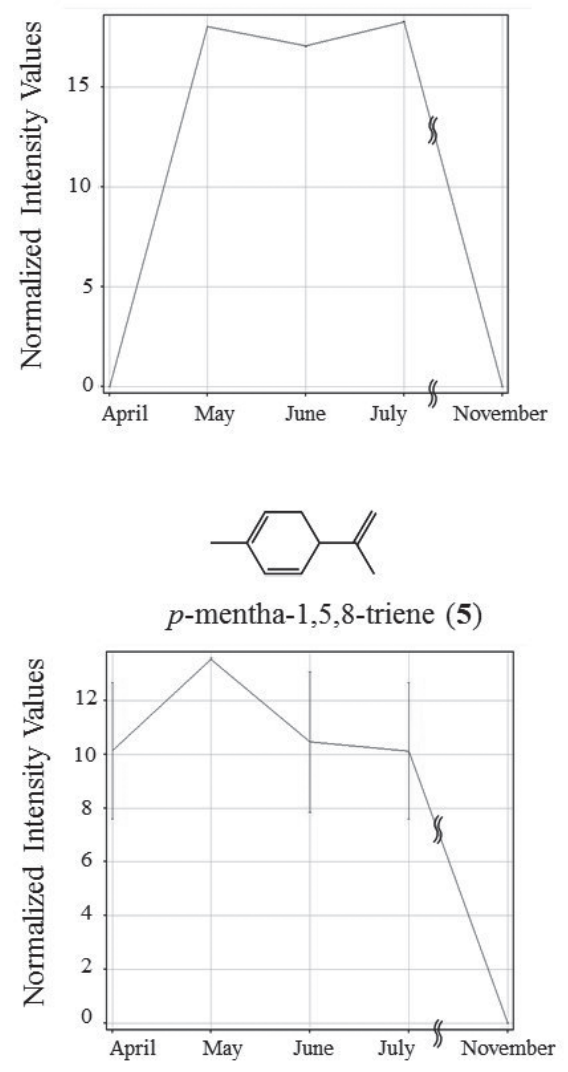
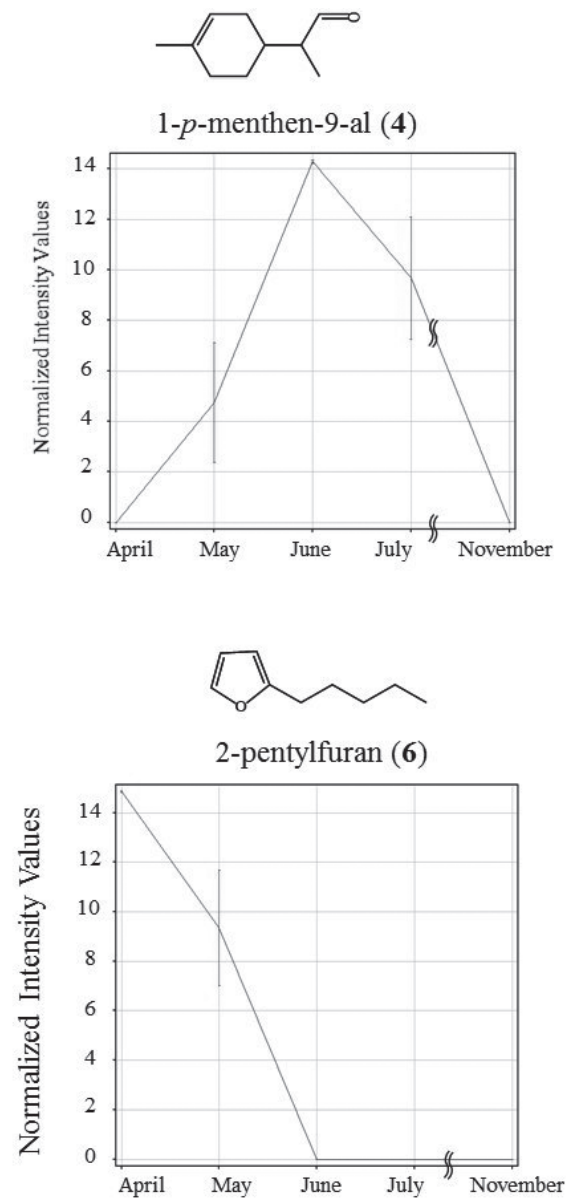

Fig. 4 Seasonal fluctuations of four major aroma components in larch foliage essential oils.

components: $(E)$-4,8-dimethyl nona-1,3,7-triene (3, 0.03\% in essential oil of May), 1-p-menthen-9-al (4, $0.01 \%$ in essential oil of May), $p$-mentha-1,5,8-triene $(5,0.01 \%$ in essential oil of May) and 2-pentylfuran (6, 0.01\% in essential oil of May) (Fig. 4). The normalized value on the vertical axis represents the value converted from the abundance of chemical compounds monitored by GC-MS with the detection of TIC in the essential oil on the log 2 scale.

The non-cyclic monoterpene hydrocarbon $(E)$-4,8-dimethyl nona-1,3,7-triene (3) was not detected in April and November, but its amount drastically increased in May, June, and July. Similarly, the monocyclic monoterpene 1-pmenthen-9-al (4) was not detected in April and November, but its amount sharply increased in May, peaked in June, and rapidly decreased in July. Conversely, the monocyclic monoterpene $p$-mentha-1,5,8-triene (5) was rich in new leaves at the early developing stage in April, but its amount declined in June and July from the peak in May. In addition, 2-pentylfuran (6) was richest in April, but its amount drastically decreased in May and became a trace amount after June. Thus, chemical components in larch foliage essential oil often show actively biosynthesized and accumulated, depending on the leaf maturation stages.

\section{Conclusion}

To summarize the results described above, the chemical compositions of aroma components in larch foliage essential oil showed clear seasonal fluctuations of volatile compounds compared with those in pine and fir foliage essential oils. The chemical composition of larch foliage essential oil collected in November, when larch leaves in Hokkaido have started senescence and their color changes to yellow, was significantly different in quality. We speculated that the drastic metabolic change in the chemical compositions in larch leaves is due to common characteristics of leaves of the deciduous trees. Since larch is also a coniferous and deciduous, its high productivity and the drastic change of turpentine oil is maintained.

\section{Acknowledgments}

We thank Ms. Miharu Ishii for help with the GC-MS analysis, Mr. Eisuke Ando and Mr. Hiroshi Ohno for the provision of larch materials, Ms. Yoshiko Sakamaki for the provision of pine materials, and Fupunomori Co., Ltd for the provision of fir materials. This research was supported by 
The Regional Innovation Creation Project (2013) by the Ministry of Economy, Trade and Industry and NOASTEC grants (2012).

\section{Conflict of Interest}

No potential conflict of interest was reported by the authors.

\section{Supporting Information}

This material is available free of charge via the Internet at http://dx.doi.org/jos.68.10.5650/jos.ess 19023

\section{References}

1) Wilbon, P.A.; Chu, F.; Tang, C. Progress in renewable polymers from natural terpenes, terpenoids, and rosin. Macromol. Rapid Commun. 34, 8-37(2013).

2) Yatagai, M.; Sato, T. Terpenes of leaf oils from conifers. Biochem. Sys. Ecol. 14, 469-478(1986).

3) Tumen, I.; Hafizoglu, H.; Kilic, A.; Dönmez, I.E.; Sivrikaya, H.; Reunanen, M. Yields and constituents of essential oil from cones of Pinaceae spp. natively grown in Turkey. Molecules 15, 5797-5806 (2010).

4) Koçak, A.; Kılıç, Ö. Identification of essential oil composition of four Picea Mill. (Pinaceae) species from Canada. J. Agric. Sci. Technol. B4, 209-214(2014).

5) Liu, Y.; Shen, J.; Zhu, X.D. Headspace solid-phase microextraction for the determination of volatile organic compounds in Larix gmelini particles. Phys. Procedia 32, 605-613 (2012).

6) Lee, J.H.; Hong, S.K. Comparative analysis of chemical compositions and antimicrobial activities of essential oils from Abies holophylla and Abies koreana. J. Microbiol. Biotechnol. 19, 372-377(2009).

7) Tohmura, S.; Miyamoto, K.; Inoue, A.; Chiba, Y. Measurement of volatile organic compounds emissions from laminas for the glue-laminated timber and domestic solid wood stored for a long term. Bull. FFPRI 4, 145-155(2005).

8) Ishikawa, A.; Ohira, T.; Miyamoto, K.; Inoue, A.; Ohkoshi, M. Mission of volatile organic compounds during drying of veneer: Red meranti (Shorea sect. Rubroshorea), larch (Larix sp.), and sugi (Cryptomeria japonica D. Don). Bull. FFPRI 8, 115-125(2009).

9) Miyazawa, N.; Tomita, N.; Kurobayashi, Y.; Nakanishi, A.; Ohkubo, Y.; Maeda, T.; Fujita, A. Novel character impact compounds in Yuzu(Citrusjunos sieb. ex Tanaka) peel oil. J. Agric. Food Chem. 57, 1990-1996 (2009). 